\title{
Neural stem cell sex dimorphism in aromatase (CYPI9) expression: a basis for differential neural fate
}

This article was published in the following Dove Press journal:

Stem Cells and Cloning: Advances and Applications

19 November 2010

Number of times this article has been viewed

\section{Jay Waldron' \\ Althea McCourty' \\ Laurent Lecanu ${ }^{1,2}$}

'The Research Institute of the McGill University Health Centre, Montreal, Canada; ${ }^{2}$ Department of Medicine, McGill University, Quebec, Canada
Correspondence: Laurent Lecanu The Research Institute of the McGill University Health Centre, 6100 Royalmount Avenue, Montreal H4P 2R2, Quebec, Canada $\mathrm{Tel}+\mathrm{I} 5142458180$

$\mathrm{Fax}+\mid \mathrm{II} 2836282$

Email laurent.lecanu@mcgill.ca
Purpose: Neural stem cell (NSC) transplantation and pharmacologic activation of endogenous neurogenesis are two approaches that trigger a great deal of interest as brain repair strategies. However, the success rate of clinical attempts using stem cells to restore neurologic functions altered either after traumatic brain injury or as a consequence of neurodegenerative disease remains rather disappointing. This suggests that factors affecting the fate of grafted NSCs are largely understudied and remain to be characterized. We recently reported that aging differentially affects the neurogenic properties of male and female NSCs. Although the sex steroids androgens and estrogens participate in the regulation of neurogenesis, to our knowledge, research on how gender-based differences affect the capacity of NSCs to differentiate and condition their neural fate is lacking. In the present study, we explored further the role of cell sex as a determining factor of the neural fate followed by differentiating NSCs and its relationship with a potential differential expression of aromatase (CYP19), the testosterone-metabolizing enzyme.

Results: Using NSCs isolated from the subventricular zone of three-month-old male and female Long-Evans rats and maintained as neurospheres, we showed that differentiation triggered by retinoic acid resulted in a neural phenotype that depends on cell sex. Differentiated male NSCs mainly expressed markers of neuronal fate, including $\beta$ III-tubulin, microtubule associated protein 2, growth-associated protein 43, and doublecortin. In contrast, female NSCs essentially expressed the astrocyte marker glial fibrillary acidic protein. Quantification of the expression of aromatase showed a very low level of expression in undifferentiated female NSCs, whereas aromatase expression in male NSCs was 14-fold greater than the female level.

Conclusion: Our results confirm our previous data that the neural phenotype acquired by differentiating NSCs largely depends on cell sex, and that differential expression of aromatase in undifferentiated NSCs might contribute to this sex-based dimorphism. Although still preliminary, our discovery may have clinical application in the development of future brain repair strategies.

Keywords: neuroregenerative medicine, brain repair strategy, sex dimorphism, aromatase, adult stem cells

\section{Introduction}

The brain is one of the main targets of gonadal steroid hormones and it contains many of the steroid-metabolizing enzymes. The effect of gonadal steroids on brain development and maturation has been well documented for decades. ${ }^{1,2}$ The literature on the subject has introduced the common belief that gonadal steroids may be the only effectors of brain sexual differentiation, overshadowing other key elements. Indeed, although there is no doubt about its importance, the dogma of the gonadal origin of somatic differentiation, including neuronal cells, usually implicitly implies that XX and 
XY cells, and therefore stem cells, are functionally equivalent unless gonadal secretions act on them in a sex-specific manner. The human Y chromosome encodes for 27 different proteins, ${ }^{3}$ eight of which are expressed in the male brain and could have a male-specific effect on the brain independent of any gonadal hormone influence. ${ }^{4,5}$ Furthermore, XX cells contain an $\mathrm{X}$ chromosome that receives a paternal genomic imprint whereas XY cells do not, a fact that is likely to contribute to autonomous differences between male and female cells. De Vries et $\mathrm{al}^{6}$ generated mice in which the testisdetermining gene, sry, was deleted from the Y chromosome and subsequently inserted onto an autosome, resulting in mice in which the development of the testis occurred independently of the complement of X or Y chromosomes. They found that although most of the sexual dimorphism correlated with the presence of testis or ovary (and therefore associated gonadal hormones), XY mice (with testes or ovaries) were more masculine than XX mice (with testes or ovaries) in the density of vasopressin-immunoreactive fibers in the lateral septum, suggesting that sex chromosome genes contribute to the development of a sex difference in the brain.

These results also suggest that one should not consider that female and male neural stem cells (NSCs) are equal and react in the same manner to a specific environment or pharmacologic agent. Furthermore, there are no data to support the a priori consideration that transplanting female or male NSCs into a male or female brain would result in the same neural differentiation and functional recovery as same-sex transplantation. Likewise, there is no reason to believe a priori that male and female NSC neurogenic properties would evolve in a sex-independent manner throughout development. Considering the dramatic and sex-specific hormonal changes occurring throughout development, one could expect the need of a sex-specific environment to be a prerequisite for successful neurogenesis.

We recently reported that aging differentially affects the neurogenic properties of male and female NSCs. ${ }^{7}$ In the present study, we explored further the role of cell sex as a determining factor of the neural fate followed by differentiating NSCs and its relationship with a potential differential expression of aromatase, the testosterone-metabolizing enzyme.

\section{Material and methods \\ Materials}

The expendables used for isolation and amplification of NSCs were DMEM/F12, Leibovitz L15 medium, B27, Neurobasal A medium, epithelial growth factor, penicillin/streptomycin, phosphate-buffered saline $1 \times$, phosphate-buffered saline $10 \times$, gentamycin, and DNAse I from Invitrogen (Carlsbad, CA, USA); papain, poly-L-ornithine, laminin, heparin, and retinoic acid from Sigma (St Louis, MO, USA); Percoll ${ }^{\circledR}$ and density marker beads from GE Healthcare (Uppsala, Sweden); bFGF from PeproTech (Rocky Hill, NJ, USA); L-glutamine from Thermo Fisher Scientific (Waltham, MA, USA); Accumax ${ }^{\circledR}$ from Innovative Cell Tech (San Diego, CA, USA); low-attachment six-well plates from Corning (Avon, France); glass-bottom chamber slides from Nunc (Rochester, NY, USA); and glass-bottom six-well plates from MatTek (Ashland, MA, USA). For Western blot, RIPA buffer was purchased from Thermo Fisher Scientific, and Criterion XT Tris- $\mathrm{HCl}$ gel 4\%-20\%, Criterion XT Bis-Tris gel 4\%-12\%, sodium dodecyl sulfate/Tris/Glycine running buffer, MES running buffer, and kaleidoscope markers from Bio-Rad (Mississauga, ON, USA). Biotinylated markers were from Cell Signaling Technology (Pickering, ON, USA). The primary antibodies used were specific to growth-associated protein (GAP)43 and $\beta$ III-tubulin clone TU-20 (Millipore, Temecula, CA, USA); doublecortin and microtubule-associated protein (MAP)2 (Cell Signaling Technology); 2',3'-cyclic nucleotide 3'-phosphodiesterase CNPase, myelin basic protein, vimentin, nestin, and actin (Abcam, Cambridge, MA, USA); and aromatase (Affinity Bioreagents, Rockford, IL, USA).

\section{Isolation and amplification of NSCs}

Male and female three-month-old Long-Evans rats were anesthetized with 3\% isoflurane and transcardiacally perfused with $250 \mathrm{~mL}$ Dulbecco's modified Eagles' medium (DMEM)/F12 medium. Following decapitation, the brains were removed and placed in $25 \mathrm{~mL}$ phosphate-buffered saline/1\% penicillin-streptomycin-gentamicin. The brains were then rinsed with another $25 \mathrm{~mL}$ of phosphate-buffered saline $1 \%$ penicillin-streptomycin-antimycotic and placed in sterile plastic Petri dishes containing Leibovitz L15 medium on ice. Using a scalpel blade, two coronal cuts were made in the area between the rhinal fissure and the hippocampus. The resulting tissue chunk was placed on its posterior surface and the cortex above the corpus callosum and surrounding the ventricles removed. ${ }^{8}$ The remaining tissue (subventricular zone) was placed in another sterile Petri dish containing L15 with $2.5 \mathrm{UI} / \mathrm{mL}$ papain, $10 \mathrm{UI} / \mathrm{mL}$ DNAse I, and $1 \%$ penicillin-streptomycin-gentamicin, and was diced into approximately $1 \mathrm{~mm}^{3}$ specimens. The diced subventricular zones were each transferred to $50 \mathrm{~mL}$ centrifuge tubes containing $25 \mathrm{~mL} \mathrm{L15}$ media 
plus $2.5 \mathrm{UI} / \mathrm{mL}$ papain, $10 \mathrm{UI} / \mathrm{mL}$ DNAse I, and $1 \%$ penicillin-streptomycin-antimycotic, and allowed to digest for 40 minutes at $37^{\circ} \mathrm{C}$ in a mixer-incubator. Following digestion, the tissue suspensions were centrifuged at 300 rpm for two minutes and pellets were resuspended in $25 \mathrm{~mL}$ DMEM/F12 containing $10 \mathrm{UI} / \mathrm{mL}$ DNAse, 2\% B27, and $1 \%$ penicillin-streptomycin-gentamicin and centrifuged at $300 \mathrm{rpm}$ for another two minutes. The supernatants were removed and replaced with $3 \mathrm{~mL} 37^{\circ} \mathrm{C}$ DMEM/F12. Following trituration with a disposable pipette, the homogenates were passed sequentially through $100 \mu \mathrm{m}, 70 \mu \mathrm{m}$, and $40 \mu \mathrm{m}$ cell strainers. The filtrated homogenates were then transferred to an autoclaved $10 \mathrm{~mL}$ centrifuge tube and the volume was increased to $4.5 \mathrm{~mL}$ with DMEM/F12, to which was added $4.5 \mathrm{~mL}$ Percoll solution (Percoll:phosphatebuffered saline $10 \times 9: 1)$. This mixture was centrifuged at $12,000 \mathrm{rpm}$ for one hour at $18^{\circ} \mathrm{C}$. Density marker beads (GE Healthcare) were used to determine the layer corresponding to the NSCs $(1.065-1.075 \mathrm{~g} / \mathrm{mL}) .{ }^{9}$ These cells were placed in a sterile $15 \mathrm{~mL}$ centrifuge tube and rinsed with $15 \mathrm{~mL}$ DMEM/F 12 at $37^{\circ} \mathrm{C}$. Following centrifugation for 10 minutes at $900 \mathrm{rpm}, 14.5 \mathrm{~mL}$ of supernatant was removed and replaced with $14.5 \mathrm{~mL}$ Neurobasal $\mathrm{A}$ at $37^{\circ} \mathrm{C}$ containing 2\% B27, $2 \mathrm{nM}$ L-glutamine, $20 \mathrm{ng} / \mathrm{mL}$ epithelial growth factor, $20 \mathrm{ng} / \mathrm{mL} \mathrm{bFGF}$, and $2 \mu \mathrm{g} / \mathrm{mL}$ heparin. The cells were centrifuged for 10 minutes at $900 \mathrm{rpm}$, and $14 \mathrm{~mL}$ of supernatant was removed and replaced with $2 \mathrm{~mL}$ of fresh Neurobasal A plus growth factors. Resuspended cells were seeded in six-well low attachment plates and incubated at $37^{\circ} \mathrm{C}$. Epithelial growth factor, $\mathrm{bFGF}$, and heparin were added to cells three times a week, and cells were rinsed with $37^{\circ} \mathrm{C}$ phosphate-buffered saline $1 \times$, resuspended in fresh $37^{\circ} \mathrm{C}$ Neurobasal A plus growth factors, and transferred to a clean, empty well once a week. First primary neurospheres appeared after 2-3 weeks. Neurospheres were split every month using Accumax.

\section{Neurosphere differentiation}

Prior to differentiation, NSCs were plated and nestin expression was assessed by immunofluorescence using a specific antibody (Abcam) in order to validate the stemness of our samples. Primary neurospheres were pipetted into glassbottom chamber slides (10-15 neurospheres per well) or six-well plates (40-50 neurospheres per well) that were coated with poly-L-ornithine and laminin. Neurospheres were then maintained in the same medium as when amplified and treated daily for 10 days with retinoic acid $1 \mu \mathrm{M}$ final concentration.

\section{Immunocytochemistry}

Neurospheres were washed three times with $37^{\circ} \mathrm{C}$ phosphatebuffered saline $1 \times$ and fixed with methanol at $-20^{\circ} \mathrm{C}$. Cells were then washed three times with phosphate-buffered saline $1 \times$ at room temperature before being blocked for one hour with donkey serum $5 \%$ in triton $100 \times 0.1 \%$ /phosphate-buffered saline $1 \times$. Neurospheres were incubated with one or several primary antibodies for 24 hours at $4^{\circ} \mathrm{C}$ in donkey serum $1.5 \%$ / triton $100 \times 0.05 \%$ /phosphate-buffered saline $1 \times$. Cells were then washed three times with phosphate-buffered saline $1 \times$ at room temperature before secondary antibodies were added for two hours at room temperature in donkey serum 1.5\%/triton $100 \times 0.05 \% /$ phosphate-buffered saline $1 \times$. After rinsing three times with phosphate-buffered saline $1 \times$, neurospheres were coverslipped using DAPI containing Vectashield ${ }^{\circledR}$ mounting medium. Fluorescence was viewed through an Olympus Fluoview FV1000 laser confocal microscope. Undifferentiated neurospheres were assayed for nestin and aromatase, and differentiated neurospheres were assayed for the neuronal markers GAP43, doublecortin, $\beta$ III-tubulin, glial fibrillary acidic protein (astrocyte marker), and CNPase and myelin basic protein (oligodendrocyte markers).

\section{Western blot}

Proteins were extracted using an RIPA buffer (RIPA lysis buffer, Thermo Fisher Scientific), and protein concentration was determined by a bicinchoninic acid method (Micro BCA $^{\text {TM }}$ Protein Assay Kit, Thermo Scientific). Samples were separated on a Criterion XT Bis-Tris gel 4\%-12\% with MES running buffer (Bio-Rad), all under reduced conditions. The gels ran for 1.5 hours at $130 \mathrm{~V}$ and were transferred onto $0.45 \mu \mathrm{m}$ polyvinylidene fluoride membranes for one hour at $65 \mathrm{~A}$ with tris/glycine transfer buffer in $20 \%$ methanol. Biotinylated and kaleidoscope markers were included in every run. Membranes were blocked with $1 \times$ casein (Vector Labs, Burlington, ON, USA) and incubated overnight at $4^{\circ} \mathrm{C}$ in primary antibody, then incubated in biotinylated secondary antibody at a dilution of 1:1000 for one hour at room temperature. An avidin biotin complex amplification (Vectastain ${ }^{\circledR}$ ABC-AmPTM, Vector Labs) was used and incubated for 10 minutes at room temperature. Membranes were equilibrated in $0.1 \mathrm{M}$ Tris buffer at $\mathrm{pH} 9.5$ and were visualized using a chemiluminescent/fluorescent substrate for alkaline phosphatase (DuoLuX ${ }^{\mathrm{TM}}$, Vector Labs) for five minutes each at room temperature. The images were detected with an imaging analysis system (Image Quant 350, GE Healthcare). Undifferentiated neurospheres were assayed for nestin and aromatase, and ratio protein of interest over actin was 
calculated to quantify protein expression. Statistical analysis was conducted by Student's $t$-test using the results obtained with NSCs isolated from three different rats for each sex.

\section{Results}

\section{Expression of neural fate markers}

Male and female undifferentiated NSCs expressed the stem cell marker nestin in equivalent amounts, as shown in Figure 1A-1C. Male neurospheres isolated from threemonth-old rats and differentiated with retinoic acid led to the expression of mainly neuronal markers, including BIII-tubulin, GAP43, and doublecortin (Figure 2F, 2N, and $2 \mathrm{~V}$, respectively). In contrast, female NSCs exposed to retinoic acid mainly expressed the astroglial markers GFAP and vimentin (Figure 2C and 2I, respectively), suggesting that in these specific and identical in vitro conditions female NSCs acquired an astrocytic phenotype. Furthermore, the oligodendrocyte marker CNPase showed a higher level of expression in retinoic acid-differentiated male NSCs than in female NSCs (Figure 2Q, 2U, and 2E) likely reflecting the need for myelinization because of new neurons formed at a

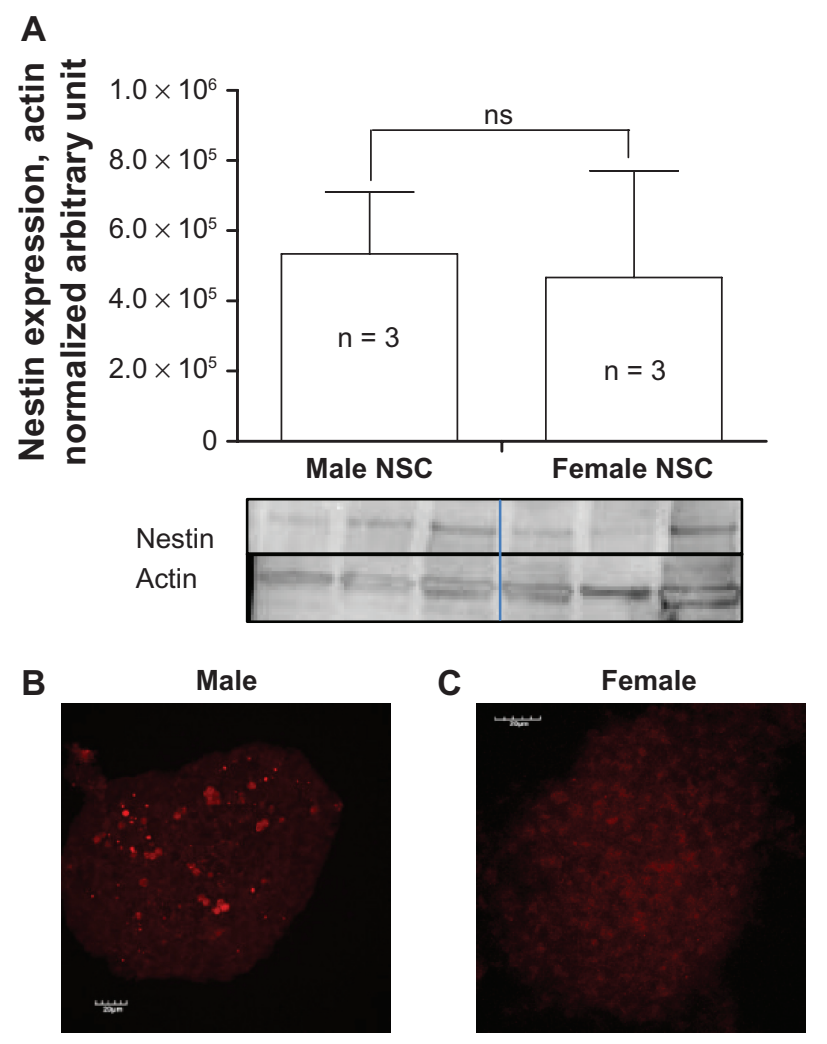

Figure I Nestin expression in undifferentiated NSCs. Quantification of nestin expression from three different rats of each gender. A) Positive nestin immunostaining in male B) and female C) NSCs cultured as neurospheres.

Note: Statistical analysis was conducted by Student's $t$-test.

Abbreviation: ns, non significant; NSC, neural stem cell. higher rate by male NSCs than female NSCs. It is noteworthy that we did not pool NSCs obtained from the animals, and bands observed on the gel reflect the expression of proteins in differentiated NSCs isolated from separate animals.

\section{Differential expression of aromatase in undifferentiated NSCs}

A weaker aromatase-positive signal (DyLight 488) was observed by immunocytochemistry in female NSCs (Figure $3 \mathrm{~K}-3 \mathrm{~S}$ ) compared with the intensity of the signal observed in male NSCs (Figure 3A-3J) as shown on consecutive confocal sections. This difference was even easier to perceive on the full stack confocal image (Figure 4B and 4C). The level of expression of aromatase was much higher in male than in female undifferentiated NSCs in which aromatase expression was barely detectable by Western blot (Figure 4A).

\section{Discussion}

As with any mammal, the human being is a sexually dimorphic species. As such, we display sex differences in various physiologic processes, including embryogenesis and neurogenesis, and in the physiopathology of several diseases and conditions, including brain stroke, cardiovascular diseases, and neuropsychiatric disorders. ${ }^{10}$ This mainly reflects the differential effect of the gonadal hormones estrogens and androgens. However, there is increasing evidence that sex-based differences might not relate only to variations of circulating sex steroid levels but also to the differential transduction mechanism of the target cell. ${ }^{11}$ We report herein that, upon stimulation by retinoic acid, the neural fate followed by adult rat NSCs is sex-dependent and is concurrent with a sex-based differential level of expression of aromatase in undifferentiated NSCs.

Differentiated male NSCs mainly expressed neuronal markers like $\beta$ III-tubulin, MAP2, GAP43, and doublecortin and a very low level of the astrocyte lineage marker GFAP. In contrast, differentiated female NSCs expressed neuronal markers at a lesser level and the astrocyte marker GFAP at a higher level than males. Retinoic acid is a member of the steroid/thyroid superfamily of signaling molecules. Its role in brain morphogenesis, differentiation, and regeneration is very well described, and its neurogenic properties have been extensively studied. ${ }^{12-14}$ However, to our knowledge, a sexbased difference in the retinoic pathway in NSCs has never been reported. More interestingly, such data suggest that sex might be a primary determining factor of NSCs' neural fate and are supported by results we recently published. Indeed, we showed that the capacity of NSCs to differentiate into a 


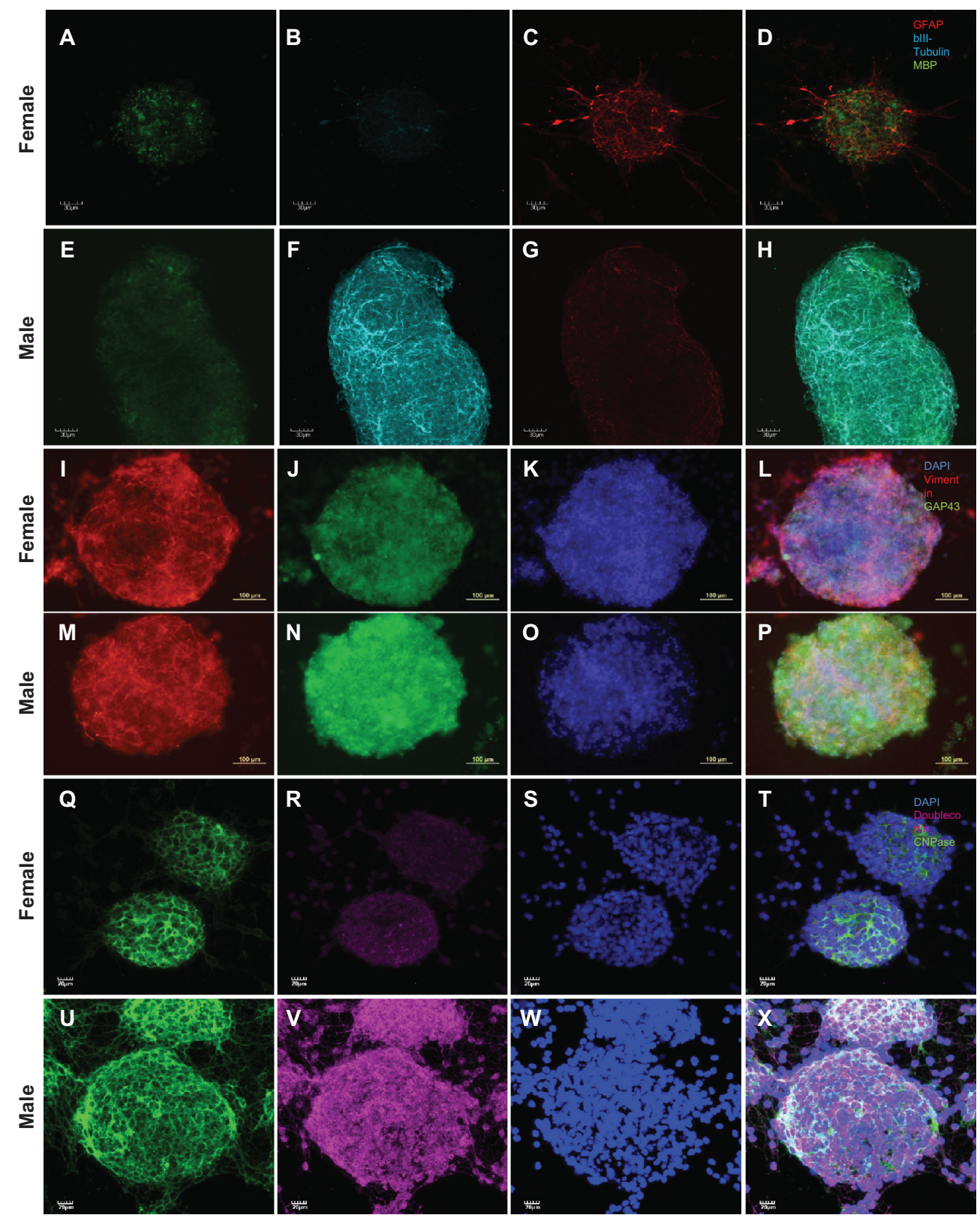

Figure 2 Retinoic acid-induced expression of neural fate markers. Male (E-H, M-P, U-X) and female (A-D, I-L, Q-T) NSCs were grown as neurospheres prior to being exposed to retinoic acid I mM for 10 days. The identification of the neural phenotypes was then performed by immunofluorescence and confocal microscopy. Myelin basic protein (A, E), Blll-tubulin (B, F), GFAP (C, G), vimentin (I, M), GAP-43 (J, N), CNPase (Q, U), doublecortin (R, V), DAPI (K, O, S, W), merge (D, H, L, P, T, X). Abbreviation: NSC, neural stem cell.

particular neural phenotype is differentially affected through aging according to sex, ${ }^{7}$ and such a role for cell sex has never been demonstrated for NSCs. However, our results are supported by recent data showing that such sex-based stem cell determinism exists in striated muscle. Indeed, cell sex as a variable that considerably affects muscle-derived stem cells' capacity to regenerate tissue has been recently proposed because female muscle-derived stem cells have been reported to have higher muscle regeneration efficiency than those of the male. ${ }^{15}$ Data generated by the same laboratory showed that, on the other hand, male muscle-derived stem cells display more chondrogenic differentiation and better cartilage regeneration than the female muscle-derived stem cells. ${ }^{13}$

Debating about sex differences cannot be done without mentioning the gonadal hormones, because it is so far the common understanding that they are, by necessity, involved in every aspect of sex dimorphism. In particular, the role of estrogens and androgens in neurogenesis has been extensively studied because they seem to have an opposite effect on neural cell ontogeny, ${ }^{16}$ although accumulating evidence is advocating for a more complex reality. ${ }^{6}$ We previously demonstrated that undifferentiated NSCs displayed a sexual dimorphism 


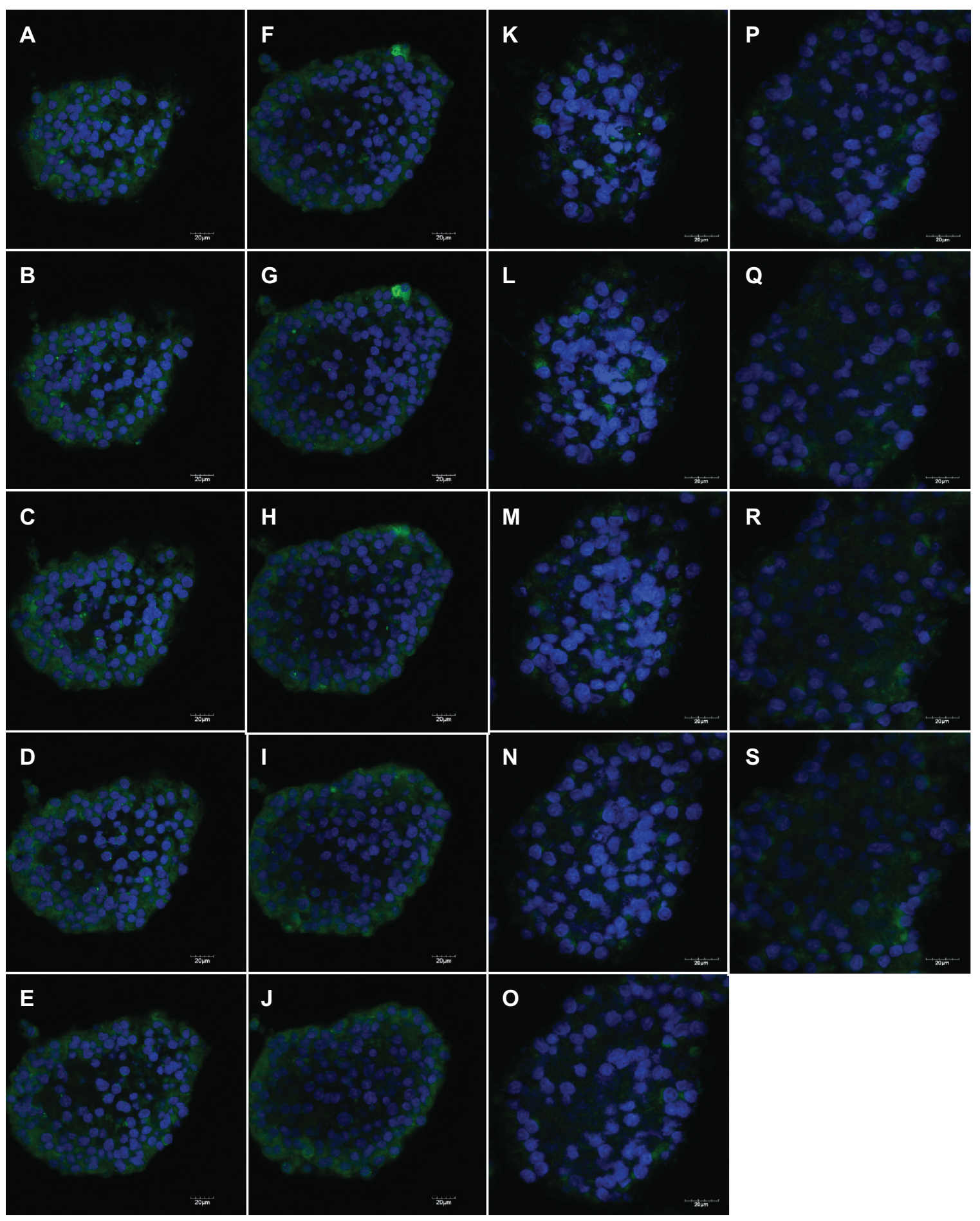

Figure 3 Aromatase differential expression in undifferentiated male and female NSCs. Aromatase expression was visualized on consecutive layers by confocal microscopy on NSCs isolated from the SVZ of three-month-old male (A-J) and female (K-S) rats and grown as neurospheres.

Abbreviations: NSC, neural stem cell; SVZ, subventricular zone.

in the expression of steroid receptors, in particular ER $\alpha$ and ER $\beta$, and the expression levels of several steroid receptors were increasing during aging. We attributed, at least in part, the sex difference in neural fate we observed in young and old NSCs to such sexual dimorphism. ${ }^{7}$
In order to explore further whether potential differences in the steroid pathway could explain the sex-based differences in NSCs' neural fate, we assessed the level of expression of aromatase, the enzyme responsible for the conversion of testosterone to estradiol. ${ }^{17}$ 
A
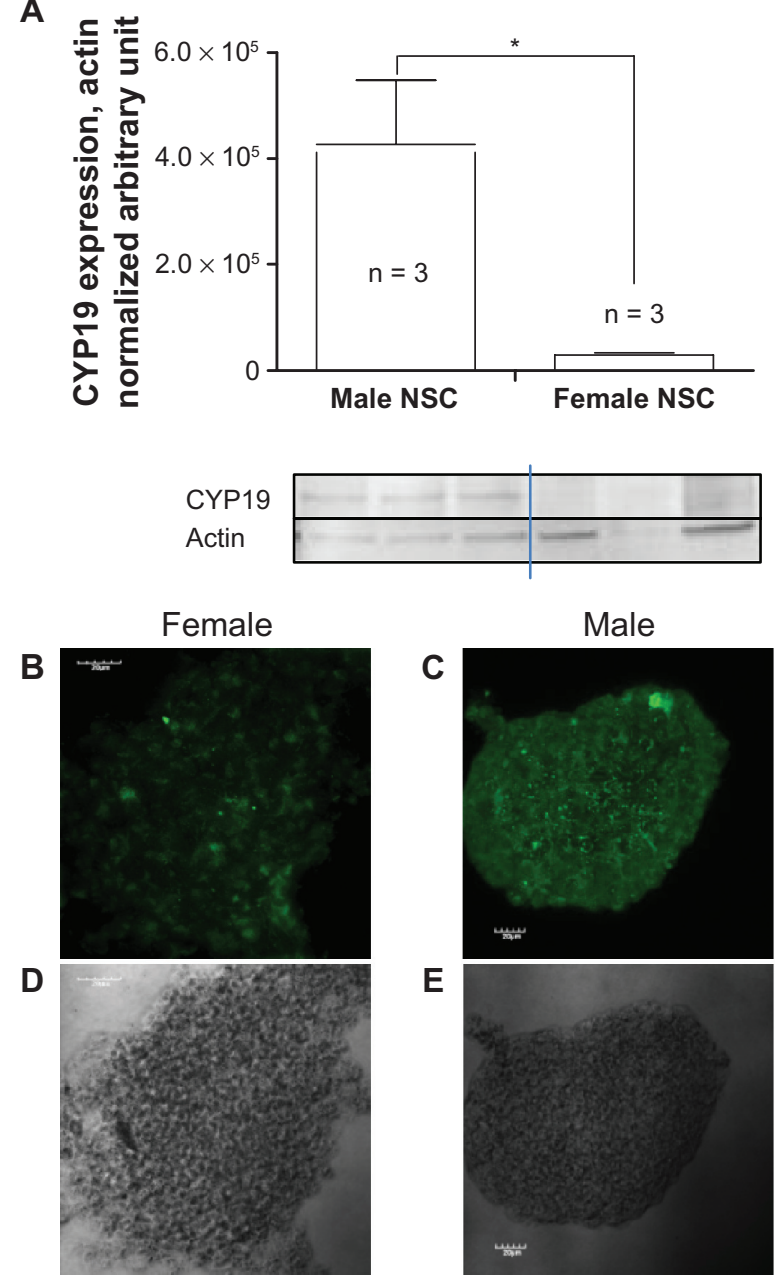

Figure 4 Quantification of aromatase expression in undifferentiated NSCs. NSCs isolated from the SVZ of three-month-old male and female rats and grown as neurospheres were then assessed for the level of expression of aromatase. A) The identification and quantification of aromatase expressed was then performed by western blot chemiluminescence using the NSCs of three different rats of each gender. Aromatase expression was also detected by immunofluorescence and confocal microscopy (B, C). Phase contrast (D, E).

Notes: Statistical analysis was conducted by Student's $t$-test. $* P<0.05$.

Abbreviation: ns, non significant; NSC, neural stem cell; SVZ, subventricular zone.

Testosterone activity is essentially carried by two pathways, either through direct activation of the androgen receptor (AR) or through its metabolism into estradiol via a reaction catalyzed by aromatase. We were unable to provide any evidence of AR protein expression in both male and female NSCs, contradicting previous reports from others. However, this apparent discrepancy could be easily explained considering that the first case report of AR expression has been made in mouse embryonic stem cells, ${ }^{18}$ which developmentally differ from adult NSCs. In a second study, AR mRNA has been detected in NSCs isolated from the adult rat subventricular zone, but these authors failed to demonstrate the presence of the protein, ${ }^{19}$ whereas they successfully demonstrated the presence of both mRNA and protein in embryonic stem cells. In addition, the AR agonist 19-nortestosterone did not reproduce in adult NSCs the proliferative effect that they observed in vitro in embryonic stem cells. Altogether, these results suggest that AR protein is expressed in embryonic stem cells and is no longer present in NSCs isolated from the subventricular zone of young adult rats. However, we determined that both male and female NSCs expressed aromatase. In addition, the level of aromatase expression in female NSCs was barely detectable, whereas it was 14 -fold higher in male NSCs. Our results are supported by previously characterized aromatase expression in progenitor cells of the ventricular layer of the zebrafish forebrain. ${ }^{20,21}$ Although our study design did not allow us to unravel the functional significance of aromatase expression in NSCs, our results suggest that such dimorphism might allow male NSCs to produce a larger amount of estradiol, with its possible role being to regulate NSCs' neural fate locally and to control sexual dimorphism through differential activation of ER $\alpha$ and $E R \beta$, a hypothesis raised decades ago to explain dimorphic sexual behavior in males. ${ }^{21,22}$ Supporting our data, aromatase sexual dimorphism has been previously reported in mature neuronal cells of the bed nucleus of mice stria terminalis and medium amygdala, where the highest level of aromatase expression was found in males. ${ }^{5}$ These authors also demonstrated that the masculinization of a number of aromatase-positive neurons was independent of testosterone signaling through AR but rather was related to estradiol synthesis through aromatase activity. ${ }^{5}$ Such a mechanism of action has been demonstrated to occur in the zebrafish brain. ${ }^{23}$ Our results unveil previously undescribed sex dimorphism of aromatase expression in NSCs.

\section{Conclusion}

Our experiments confirmed our previous data that cell sex is a major factor of neural fate determinism for NSCs isolated from the subventricular zone of young adult rats. In addition, our results suggest that the sexual dimorphism of aromatase expression might play a key role in this sex-based difference. Further studies are required to unravel fully its functional significance. However, such a largely underexplored aspect of NSC biology will certainly have to be taken into an account for the development of future stem cell therapy as a brain repair strategy.

\section{Acknowledgments}

This work was funded by a Royal Victoria Hospital Award and by a Canadian Institutes of Health Research catalyst grant IAP 92827. 


\section{Disclosure}

The authors report no conflicts of interest in this work.

\section{References}

1. Phoenix $\mathrm{CH}$, Goy RW, Gerall AA, et al. Organizing action of prenatally administered testosterone propionate on the tissues mediating mating behavior in the female guinea pig. Endocrinology. 1959;65:369-382.

2. Smith ER, Davidson JM. Differential responses to hypothalamic testosterone in relation to male puberty. Am J Physiol. 1967;212: $1385-1390$.

3. Skaletsky H, Kuroda-Kawaguchi T, Minx PJ, et al. The male-specific region of the human $\mathrm{Y}$ chromosome is a mosaic of discrete sequence classes. Nature. 2003;423:825-837.

4. Maxson SC. Searching for candidate genes with effects on an agonistic behavior, offense, in mice. Behav Genet. 1996;26:471-476.

5. Xu J, Burgoyne PS, Arnold AP. Sex differences in sex chromosome gene expression in mouse brain. Hum Mol Genet. 2002;11:1409-1419.

6. de Vries GJ, Rissman EF, Simerly RB, et al. A model system for study of sex chromosome effects on sexually dimorphic neural and behavioral traits. J Neurosci. 2002;22:9005-9014.

7. Waldron J, McCourty AM, Lecanu L. Aging differentially affects male and female neural stem cell neurogenic properties. Stem Cells Cloning Adv Appl. 2010;3:119-127.

8. Laywell ED, Kukekov VG, Suslov O, et al. Production and analysis of neurospheres from acutely dissociated and postmortem CNS specimens. Methods Mol Biol. 2002;198:15-27.

9. Palmer TD, Markakis EA, Willhoite AR, et al. Fibroblast growth factor-2 activates a latent neurogenic program in neural stem cells from diverse regions of the adult CNS. J Neurosci. 1999;19(19):8487-8497.

10. Gold JH. Gender differences in psychiatric illness and treatments: A critical review. J Nerv Ment Dis. 1998;186:769-775.

11. McCarthy MM, Auger AP, Bale TL, et al. The epigenetics of sex differences in the brain. J Neurosci. 2009;29:12815-12823.
12. Lane MA, Bailey SJ. Role of retinoid signalling in the adult brain. Prog Neurobiol. 2005;75:275-293.

13. Matsumoto T, Kubo S, Meszaros LB, et al. The influence of sex on the chondrogenic potential of muscle-derived stem cells: Implications for cartilage regeneration and repair. Arthritis Rheum. 2008;58:3809-3819.

14. Rawson NE, LaMantia AS. Once and again: Retinoic acid signaling in the developing and regenerating olfactory pathway. $J$ Neurobiol. 2006;66:653-676.

15. Deasy BM, Lu A, Tebbets JC, et al. A role for cell sex in stem cell-mediated skeletal muscle regeneration: Female cells have higher muscle regeneration efficiency. J Cell Biol. 2007;177:73-86.

16. Galea LA, Spritzer MD, Barker JM, et al. Gonadal hormone modulation of hippocampal neurogenesis in the adult. Hippocampus. 2006; 16:225-232.

17. Townsley JD, Rubin EJ, Crystle CD. Evaluation of placental steroid 3 -sulfatase and aromatase activities as regulators of estrogen production in human pregnancy. Am J Obstet Gynecol. 1973;117:345-350.

18. Chang CY, Hsuuw YD, Huang FJ, et al. Androgenic and antiandrogenic effects and expression of androgen receptor in mouse embryonic stem cells. Fertil Steril. 2006;85 Suppl 1:1195-1203.

19. Brannvall K, Bogdanovic N, Korhonen L, et al. 19-Nortestosterone influences neural stem cell proliferation and neurogenesis in the rat brain. Eur J Neurosci. 2005;21:871-878.

20. Pellegrini E, Mouriec K, Anglade I, et al. Identification of aromatasepositive radial glial cells as progenitor cells in the ventricular layer of the forebrain in zebrafish. J Comp Neurol. 2007;501:150-167.

21. MacLusky NJ, Naftolin F. Sexual differentiation of the central nervous system. Science. 1981;211:1294-1302.

22. Naftolin F, Ryan KJ. The metabolism of androgens in central neuroendocrine tissues. J Steroid Biochem. 1975;6:993-997.

23. Mouriec K, Gueguen MM, Manuel C, et al. Androgens upregulate cyp19a1b (aromatase B) gene expression in the brain of zebrafish (Danio rerio) through estrogen receptors. Biol Reprod. 2009;80:889-896.
Stem Cells and Cloning: Advances and Applications

\section{Publish your work in this journal}

Stem Cells and Cloning: Advances and Applications is an international, peer-reviewed, open access journal. Areas of interest in stem cell research include: Embryonic cell stems; Adult stem cells; Blastocysts; Cordblood stem cells; Stem cell transformation and culture; Therapeutic cloning; Umbilical cord blood and bone marrow cells; Laboratory,

\section{Dovepress}

animal and human therapeutic studies; Philosophical and ethical issues related to stem cell research. This journal is indexed on CAS. The manuscript management system is completely online and includes a quick and fair peer-review system. Visit http://www.dovepress.com/ testimonials.php to read real quotes from published authors. 